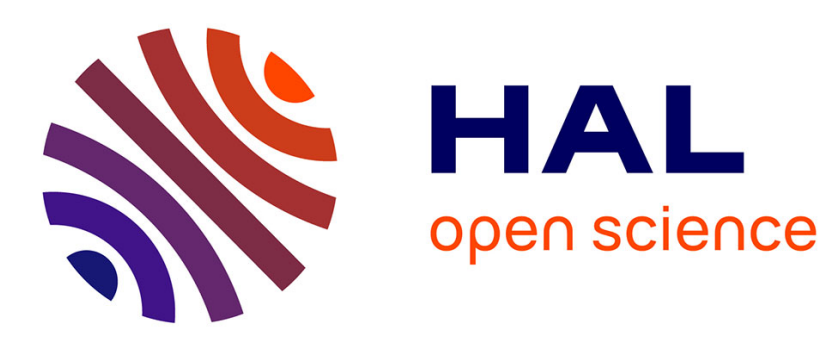

\title{
Sustainable E-Learning - A Case Study on the Pros and Cons of Certification
}

\author{
Bent B. Andresen
}

\section{To cite this version:}

Bent B. Andresen. Sustainable E-Learning - A Case Study on the Pros and Cons of Certification. 1st International Conference on Sustainable ICT, Education, and Learning (SUZA), Apr 2019, Zanzibar, Tanzania. pp.30-38, 10.1007/978-3-030-28764-1_5 . hal-02515744

\section{HAL Id: hal-02515744 \\ https://hal.inria.fr/hal-02515744}

Submitted on 23 Mar 2020

HAL is a multi-disciplinary open access archive for the deposit and dissemination of scientific research documents, whether they are published or not. The documents may come from teaching and research institutions in France or abroad, or from public or private research centers.
L'archive ouverte pluridisciplinaire HAL, est destinée au dépôt et à la diffusion de documents scientifiques de niveau recherche, publiés ou non, émanant des établissements d'enseignement et de recherche français ou étrangers, des laboratoires publics ou privés. 


\title{
Sustainable e-Learning - a Case Study on the Pros and Cons of Certification
}

\author{
Bent B. Andresen ${ }^{\text {[0000-0002-6448-955X] }}$ \\ Danish School of Education, Aarhus University, Tuborgvej 164, 2400 Copenhagen NV, \\ Denmark \\ bba@edu.au.dk
}

\begin{abstract}
This paper deals with a case study on how to achieve sustainable elearning through systematic certification. The case is a nationwide Danish project on the certification of 23 vocational e-learning courses conducted by 'The National Danish Knowledge Centre of e-learning' in 2018.

The research objective is to investigate the pros and cons of this e-learning certification. How and why does it promote sustainable e-learning and professional development among teachers in vocational education and training?

The research results provide evidence suggesting that the certification increases the sustainability of vocational e-learning. In particular, it promotes consistency between expected learning outcomes, preconditions as regards content, duration, flexibility, use of digital platform etc., and design in terms of organization and evaluation of learning activities.

The certification of e-learning also fosters professional development among the teachers involved. They appreciate the systematic nature of the certification process and the template applied as well as the provision of supportive and specific feedback from the certifier.

When the vocational teachers were assigned the role as e-learning designers, they stepped out of their comfort zone. In these cases, they greatly appreciated receiving supportive and challenging feedback. The combination of support and pressure helped them move forward towards new experiences and broader repertoires of sustainable e-learning methods.

In particular, the teachers benefitted from single-loop learning, which improved their planning actions, and double-loop learning, which improved their beliefs about sustainable e-learning. These results can be generalized and expanded to other projects. Consequently, the certification is important for the future development of sustainable e-learning.
\end{abstract}

Keywords: E-learning, certification, vocational teachers, capacity building

\section{Introduction}

The paper deals with a project on e-learning certification at vocational colleges, which was carried out to promote the sustainability of e-learning. In this context, the term 'sustainable e-learning' is used as an umbrella term for various persistent quality aspects of e-learning. Focus is on the sustainability of e-learning instead of e-learning 
for sustainability, i.e. education aimed at future development of the global environment, the climate etc.

Sustainability issues like the cost-effectiveness and usability of digital tools, platforms, and materials are outside the scope of the research. Rather, it deals with the sustainability of technology-enhanced vocational education that is flexible with respect to time and place. In this context, the notion of e-learning is used as an overarching term encompassing blended learning as well as purely distance learning.

\subsection{Certification process}

In general, there are many visions regarding sustainable e-learning to be considered [1]. These visions include current vocational education and training (VET). Dealing with technological sustainability, the VET system takes into account ideas of increased flexibility and frequent use of digital technology.

Dealing with social and cultural sustainability, the system also takes into account constantly changing educational needs among participants in vocational youth and inservice education. Therefore, the certification project promotes precise descriptions of potential participants' various learning conditions and needs. The project also promotes explicit preconditions regarding content, duration, flexibility etc. Furthermore, it promotes consistent design, including organization and evaluation of learning activities.

The certified courses cover a spectrum from primarily face-to-face education to primarily online education. With an average of 59 hours, the course duration varies from 4 to 185 hours (see Fig. 1).

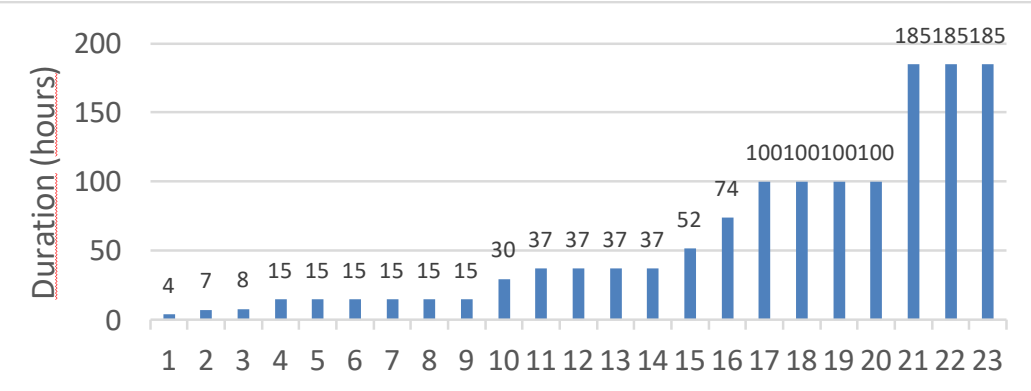

Fig. 1. Certified vocational e-learning courses

The certification project was launched in 2018 by 'The Danish Organization of Business Schools' (DEL) and the certification agency 'The Danish National Centre for e-learning'. In cooperation with the researcher (the author of this article), the certifier developed certification guidelines for qualifying e-learning at vocational colleges.

According to these guidelines, the certification process includes three main phases. First, the designer of vocational e-learning submits a draft concept to the certifier. The designer then receives supportive and specific feedback from the certifier to promote 
well-founded and sustainable e-learning. Then the designer uses this feedback to revise and refine the concept prior to bringing it into use.

The designers of vocational e-learning describe and submit their concept using a template provided by the certifier. The main themes in this template are based on an analysis of the main factors influencing the participants' learning outcomes [2]. The main themes are:

- Terms of the course

- Learning objectives of the course

- Participant's prior learning

- Organization of the course

- Activities and learning methods

- Assessment of the course

The vocational colleges are encouraged to use this template to increase the likelihood of successful learning outcomes for all participants. Most often, the learning objectives and course duration are determined by regional or national authorities. The developers of e-learning in the VET system are encouraged to explicate these objectives and make them understandable to potential participants. In addition, the developers have to explicate the organization of e-learning. For example, they have to clearly describe the relationship between face-to-face and online activities as well as the participants' individual and collaborative learning activities.

During the planning process, the developers are also encouraged to consider the participants' previous experiences, knowledge, and skills. For example, some participants in e-learning focusing on accounting principles and methods may already have a job as an accountant.

Moreover, the developers are encouraged to take into account general preconditions, such as the participants' oral, reading, and digital skills. About $25 \%$ of the population in Denmark aged 18-65 do not have functional reading skills and thus have trouble reading to learn something new.

By contrast, digital literacy is rarely a challenge. In Denmark, digital technology is used daily in connection with learning, and the 'bring your own device' principle has been fully implemented at all levels of the educational system for several years now. Among the participants, distraction from social networks and other non-curricular digital activities are, however, a challenge which many schools are currently struggling to overcome.

\section{Research Objective}

The overall research objective is to investigate the pros and cons of e-learning certification. Does the certification process support and promote sustainable development of e-learning in the VET system?

Moreover, the research objective is to investigate the perceived usefulness of this certification among the developers of vocational e-learning. Does it support and promote capacity building among these developers?

The program theory is shown in Fig. 2. 


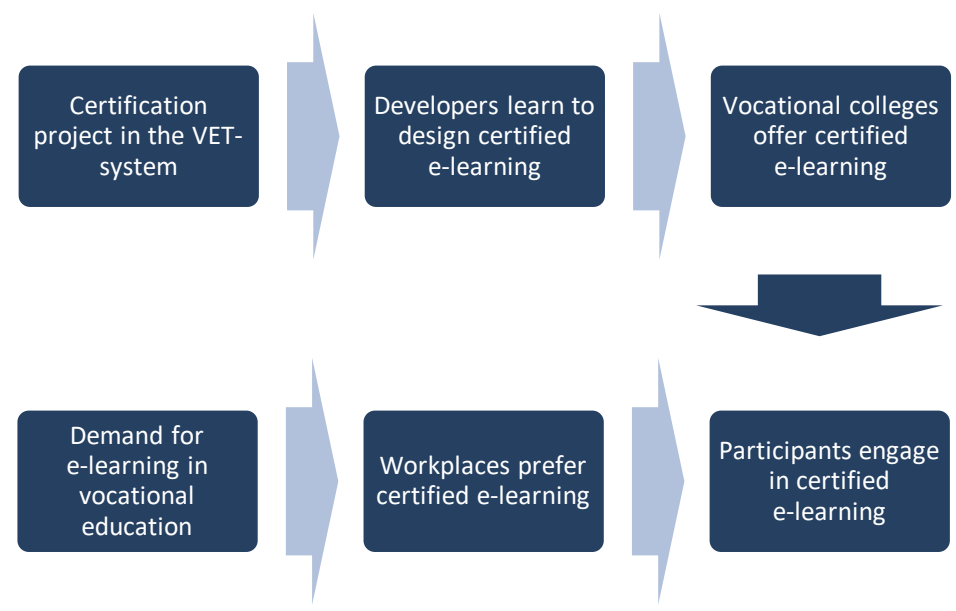

Fig. 2. Program theory

The upper row representing college level illustrates the potential influence of the certification project on the developers' professional development. Before that, their experiences in the area of e-learning varied. Some, but not all, had previous experience designing vocational e-learning. However, they all learned to design elearning. In particular, they became better at creating certified e-learning, and in the end, they all succeeded, resulting in the 23 certified courses.

The bottom row in Fig. 2 represents the demand for vocational e-learning courses. This demand is expected to increase due to government initiatives encouraging timely and work-based vocational education. In the future, the demand is also expected to increase as workplaces become aware of and prefer certified courses.

\section{$2.1 \quad$ Research methods}

The upper row representing college level illustrates the potential influence of the certification project on the developers' professional development. Before that, their experiences in the area of e-learning varied. Some, but not all, had previous experience designing vocational e-learning. However, they all learned to design elearning. In particular, they became better at creating certified e-learning, and in the end, they all succeeded, resulting in the 23 certified courses.

The bottom row in Fig. 2 represents the demand for vocational e-learning courses. This demand is expected to increase due to government initiatives encouraging timely and work-based vocational education. In the future, the demand is also expected to increase as workplaces become aware of and prefer certified courses.

\subsection{Research methods}

The case study is based on a mixed methods design. The methods used include semistructured interviews with staff representatives in charge of e-learning initiatives as 
well as document analyses, i.e. analyses of descriptions and communication with the certifier regarding the 23 e-learning courses.

At the vocational colleges involved, the developers in charge of the development of the 23 e-learning courses had different positions and roles. Generally, they were supported by their team leader or immediate manager (distributed leadership).

In a few cases, the developers had been assigned the role as 'e-consultants' responsible for developing but not for running the course. In most cases, the certification was carried out by either individual teachers or small teams of teachers who would run the courses afterwards.

The teachers worked together in communities of practice. For example, three teachers each developed a certified course during regular meetings with a team leader and an 'e-consultant'. At another vocational college, a team of three teachers developed three certified courses while they were informally lead by one of the teachers who had substantial experience with vocational e-learning.

A third example concerns three colleges, which had each appointed a teacher. The three teachers then worked together on a certified e-learning course to be implemented by each of the three colleges afterwards.

In general, the teachers and e-consultants involved were intrinsically motivated due to personal interest in e-learning as well as inspiration from their colleagues, team leaders, and immediate managers. Their extrinsic motivation was related to expectations from team leaders and managers at the vocational colleges. For example, some developers participated in the certification project because they wanted to change roles from regular teacher to 'e-consultant' and some even considered further career development.

\section{$3 \quad$ Research Findings}

The research findings include new knowledge about the intended and unintended consequences of the certification process. In general, the perceived utility value of the systematic design of sustainable e-learning and the support and feedback from the certifier was high. The developers of e-learning involved at the vocational colleges appreciated the certification due to several reasons, which will be briefly described in the following.

First, the teachers involved express in the interviews that they consider the certification a relevant and valuable means of improving e-learning concepts.

Second, the certification fosters their professional development. They learn from the systematic development of sustainable e-learning and the associated dialog with the certifier. For example, they develop their knowledge about sustainability and other highly relevant e-learning issues.

Third, they generally consider the certification template useful. In the future, most developers will apply this template when designing e-learning courses. Some of the developers will use a similar template and some prefer to customize it a little bit.

Fourth, the certification is generally appreciated by the HR Departments in companies employing potential participants in vocational e-learning. 
Fifth, these potential participants are assigned a more clearly defined role than before the certification project.

Sixth, the teachers learn to consider and describe more clearly than before what learning activities the participants are engaged in during the courses and what the specific learning objectives are. For example, a teacher involved in the certification project emphasizes that:

"They have ... elaborated more on the target group than in their own [previous] templates ... and they have included the learning objectives by going a little deeper into what they do".

Seventh, the developers learn to consider and describe the assessment of e-learning activities more clearly. The teachers describe the assessment methods applied in a particular course more systematically than they did before the certification project. For example, a teacher plans to conduct regular assessments during the e-learning course:

"The students will be assessed on each topic, whether they will get verbal feedback or online instruction. Sometimes the teachers give group feedback. ...They have clarified that for every single assignment. It's important to the students because they don't actually meet them”.

Another teacher emphasizes the close relationship between learning objectives and the assessment methods applied:

"The assessment refers back to the learning objectives. After working intensely on them, we would look at them as we developed assignments for the topics and considered: 'What is it actually that we want to see that you are capable of once you have achieved the learning objectives?’”

Since the provision of feedback to participants in the e-learning courses is considered an integrated part of the assessment, the developers of e-learning are expected to describe their provision of feedback in detail. Teachers who at first neglected this were encouraged by the certifier to reconsider their provision of feedback and re-submit their description:

"You should go into more detail in your description of the feedback: What will the feedback consist of (e.g. type)? How will the feedback be provided (by whom and how?)?”

Eighth, the dialog with the certifier fosters capacity building among the developers of e-learning. In general, the developers appreciate the various comments they receive from the certifier on their draft concepts. In particular, the certifiers' submission of supportive and specific feedback promotes coherence between 1) learning goals, 2) organization of blended learning activities, and 3) formative and summative assessment of these activities.

Ninth, the certifier comments on the reasons given by the developers for the specific organization of the courses. In general, the developers submit two types of 
reasons, i.e. explicit and implicit reasons. Explicit reasons require that key decisions in the organization of e-learning are clearly described and justified.

Out of the 23 certified courses, ten contain explicit reasons that include the need to learn about information retrieval, create close links between theory and practice, support collaborative learning, and provide project guidance.

Implicit reasons for e-learning include consistency between the participants' prior knowledge and ability, their expected learning outcomes, and choices of organization and assessment methods. Implicit reasons also include given requirements for using digital technology, allowing greater flexibility through participation from home or a workplace.

In principle, implicit reasons can be difficult to communicate to colleagues who want to realize or further develop the courses. However, they may be rather obvious in practice. For example, the internship part of some vocational training programs can best be done by participating in dedicated facilities using suitable forklifts, kitchen facilities, accounting applications, etc.

In such cases, face-to-face learning activities at the vocational school are required. However, the developers have to justify the extent and nature of interaction in physical and digital learning environments.

Tenth, an unintended consequence was a significant lack of knowledge about elearning methodology among a handful of the developers involved. These new elearning developers all had experience with face-to-face teaching, and they were familiar with the approach called 'direct instruction' [3]. Moreover, they had extensive knowledge about the learning content but not about approaches combining face-to-face and online activities. Therefore, they experienced some challenges when asked to organize blended learning for specific groups of participants based on specific learning objectives.

To overcome these challenges, the certifier was in charge of some hours of inservice education focusing on proper description of learning objectives, well-founded organization of blended and collaborative learning, assessment methods, and the provision of formative feedback. In order to prevent such challenges in the future, entry-level educational knowledge among the developers of e-learning could be ensured.

In general, the teachers involved are experiencing balanced pressure and support, which helps them gain new experiences and broader repertoires of sustainable elearning methods.

\section{$4 \quad$ Discussion}

There is research evidence suggesting that the learners' outcome of blended learning is generally greater than the outcome of merely face-to-face education or merely online learning, but the learning outcome highly depends on the participants' time on task and thus the developers' planning of such tasks [4]. Two other factors influencing the learning outcome are 'clear learning objectives' and 'teacher clarity' regarding information about planned learning activities [3]. Due to the previously 
mentioned lack of reading literacy among the participants in e-learning courses, a fourth sustainability factor is the vocational colleges' provision of digital video materials complementing text-based learning materials [5]. Depending on the learning objectives, at fifth major factor is learning in 'communities of practice' [6].

Teachers involved in the certification project are encouraged to carefully consider these factors when they design vocational e-learning. They participate as 'learners' engaging in focused and purposeful practice [7]. In general, they participate as a 'team' and learn from each other about sustainable e-learning approaches.

Since there is research evidence suggesting that teachers at vocational colleges seldom receive feedback on their teaching and organization of learning activities [8], the certification helps overcome this problem.

As discussed above, the teachers involved typically stepped out of their comfort zone when they were assigned the role as designers of vocational e-learning. In these cases, they greatly appreciated receiving formative and challenging feedback. In particular, they received supportive and specific feedback, including answers to questions, guidance, and supportive and specific comments on draft e-learning concepts.

Moreover, they engaged in single- and double-loop learning (see Fig. 3).

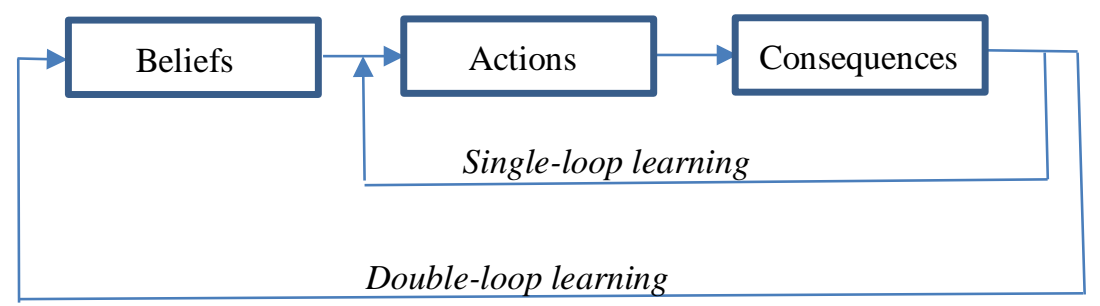

Fig. 3. Single- and double-loop learning [7].

According to the Theory of Action, three variables must be reconciled, i.e. beliefs, actions, and consequences. Single-loop learning refers to the relationship between actions (draft e-learning submitted to the certifier) and consequences (specific and supportive feedback from the certifier).

Double-loop learning refers to the developers' beliefs about sustainable e-learning. For example, the developers reflected on, questioned, and revised these beliefs causing changes in their theories of actions related to e-learning, thereby resulting in altered actions and improved design outcomes.

These results can be generalized to other projects. The findings in the case study probably also apply to other similar cases [9]. The certification is thus important for future development of sustainable e-learning.

\section{Conclusion}

This paper deals with the certification of vocational e-learning. It reports findings from a case study on systematic certification of 23 different e-learning courses, 
covering a spectrum from primarily face-to-face education to primarily online education. The average course duration is 59 hours.

The overall research objective is to investigate the pros and cons of e-learning certification. In particular, the research objective is to investigate how the certification supports and promotes sustainable development of e-learning in the VET system.

Additionally, the research objective is to investigate how the certification supports and promotes capacity building among the developers of e-learning in this system.

The certification process was launched in 2018 by the certifier 'The Danish National Centre for e-learning'. In cooperation with the researcher, the certifier forwarded guidelines and a template for qualifying e-learning at vocational schools for certification. The template was based on research findings regarding factors with a high degree of influence on the learners' outcomes in vocational education.

The research findings include new knowledge about the intended and unintended consequences of the project. First, the research provides evidence suggesting a high relevance of the presented efforts ensuring the sustainability of vocational e-learning. In general, developers of vocational e-learning appreciate the systematic and associated dialog with the certifier.

Second, the research provides evidence suggesting that their dialog with colleagues and the certifier, including the associated feedback, fosters capacity building at the vocational school. This feedback regards, among other things, the coherence between learning goals, organization of blended learning activities, and formative and summative assessment of these activities.

The developers engaged in single-loop learning, which improved their planning actions, and double-loop learning, which improved their beliefs about sustainable elearning. During some of these learning loops, the developers stepped out of their comfort zone.

Some teachers even stepped out of their zone of proximal development. In order to prevent such unintended consequences in the future, entry-level knowledge about learning objectives, formative evaluation, and e-learning methods among the developers of e-learning could be ensured.

Generally, the developers involved experienced balanced pressure and support. The research findings can be generalized to other projects regarding systematic provision of guidance and formative feedback from a certification agency. Consequently, the certification project is important for the future development of sustainable e-learning.

\section{References}

1. Christensen, C. M. \& Eyring, H. J. (2011). The innovative university. Changing the DNA of higher education from the inside out. San Francisco: Josey-Bass.

2. Andresen, B. B. (2019). Formative research on e-learning certification. Viby J.: The National Danish Knowledge Centre of e-learning. https://ec.europa.eu/epale/en/resourcecentre/content/formative-research-e-learning-certification.

3. Hattie, J. A. C. (2009). Visible Learning. A Synthesis of Over 800 Meta-Analyses Relating to Achievement. Abingdon: Routledge. 
4. Means, B. et al. (2009). Evaluation of Evidence-Based Practices in Online Learning. A Meta-Analysis and Review of Online Learning Studies. Washington, D.C.: U.S. Department of Education. http://www2.ed.gov/rschstat/eval/tech/evidence-basedpractices/finalreport.pdf.

5. Hattie, J. A. C. (2012). Visible Learning for Teachers. Maximizing Impact on Learning. Oxford: Routledge.

6. Lave, J. \& Wenger, E. (1991). Situated learning - legitimate peripheral participation. New York: Cambridge University Press.

7. Fullan, M. (2019). Nuance. Why some leaders succeed and others fail. London: Corwin.

8. OECD. (2013). TALIS 2013. Copenhagen: EVA, https://www.eva.dk/projekter/2014/talis2013/download-rapport/talis-2013-oecds-laerer-og-lederundersogelse/download.

9. Flyvbjerg, B. (2006). Five misunderstandings about case-study research. Qualitative Inquiry, vol. 12, no. 2. Pp. 219-245. 